\title{
Preparation and characterization of porous silicon photoelectrode for dye sensitized solar cells
}

\author{
K. Gangadevi ${ }^{1}$, K. Ramachandran ${ }^{2}$, R. Srinivasan ${ }^{1, *}$ \\ ${ }^{1}$ Department of Physics, Thiagarajar College, Madurai-625009, India \\ ${ }^{2}$ School of Physics, Madurai Kamaraj University, Madurai-625021, India \\ kdevi.ganga@gmail.com, thirumalchandran@gmail.com, ${ }^{*}$ r_srini2067@yahoo.co.in
}

\author{
PACS 81.05.Rm, 82.33.Ln, 88.40.jr, 88.40.hj, 78.55.Mb \\ DOI 10.17586/2220-8054-2016-7-4-629-632
}

\begin{abstract}
Nanostructured porous silicon (PS) samples were prepared by electrochemical anodic dissolution of doped silicon (p-Si) of (100) orientation at constant current density of $30 \mathrm{~mA} / \mathrm{cm}^{2}$ for different etching times 10 and $60 \mathrm{~min}$. The samples were characterized by XRD and SEM. The particle size was calculated from XRD using Scherrer's approximation are in the range of 12 to $61 \mathrm{~nm}$ and the SEM images confirmed the difference in porosities of the sample. The samples were sensitized with chloroaluminium phthalocyanine (ClAlPc) to fabricate Dye-sensitized solar cells (DSSCs). The bandgaps from UV- Vis and photoluminescence measurements are in the range of 1.5 to $1.8 \mathrm{eV}$. The photocurrent and photovoltage of the cells were measured using Keithely source meter. The maximum conversion efficiency of $2.8 \%$ is observed and results are discussed.
\end{abstract}

Keywords: Porous silicon, Chloroaluminum Pc, dye sensitized solar cells, photoluminescence.

Received: 5 February 2016

Revised: 10 May 2016

\section{Introduction}

Dye-sensitized solar cells (DSSCs) are regarded as a promising low cost option to the conventional solid-state semiconductor solar cells, due to the use of relatively cheap materials and the easy manufacturing techniques. A very important component of DSSCs is the photoelectrode, which includes a nanocrystalline porous wide bandgap oxide semiconductor layer with large internal surface area. The Commercial solar cells are fabricated using crystalline silicon which is costly in nature, where the maximum efficiency of $24.5 \%$ is reported in literature [1]. In this work, we measured the conversion efficiencies of DSSCs prepared from porous silicon with different porosities.

\section{Experimental}

Porous silicon samples were prepared by electrochemical etching of p-type (100) silicon wafers (thickness $517 \mu \mathrm{m}$ and resistivity $0.2-0.5 \Omega \mathrm{cm}$ ) at a constant current density of $30 \mathrm{~mA} / \mathrm{cm}^{2}$ for etching periods of 10 and 60 minutes [2]. To sensitize the porous samples, the dye solution was prepared by mixing the synthesized ClAlPc dye [3] in $5 \mathrm{ml}$ of ethanol and used for preparation of photoanode (ClAlPc/PS). The photoanodes were characterized by X-Ray Diffraction (XRD), Scanning Electron Microscopy (SEM), Ultraviolet-visible spectroscopy (UV-vis) and Photoluminescence (PL) techniques. The ClAlPc/PS photoanodes with different porosities were used to fabricate DSSCs.The I-V measurements were carried out to calculate the solar efficiencies using Keithley Source Meter 2400 .

\section{Results and discussion}

\subsection{XRD measurement}

The XRD patterns of PS and ClAlPc/PS prepared at constant current density of $30 \mathrm{~mA} / \mathrm{cm}^{2}$ with etching times 10 and $60 \mathrm{~min}$ is shown in Fig. $1 \mathrm{~A}$ and $\mathrm{B}$ respectively.

In Fig. 1A, the characteristic peaks at $2 \theta=24.82^{\circ}$ and $64.77^{\circ}$ depict the porous nature of silicon, which are identified as (111) and (404) plane respectively and are in agreement with JCPDS (27-1402) values [4]. The peak $2 \theta=6.31^{\circ}$ for ClAlPc in Fig. 1B agrees well with the reported value [5] and identified as the $(200)$ plane of $\alpha$-phase structure and the lattice spacing $\mathrm{d}=12.88 \AA$. Additionally, it is noted that the intensities of the peaks increase with etching time and hence the porosity, as the porosity increases with etching time [6]. The broadened 


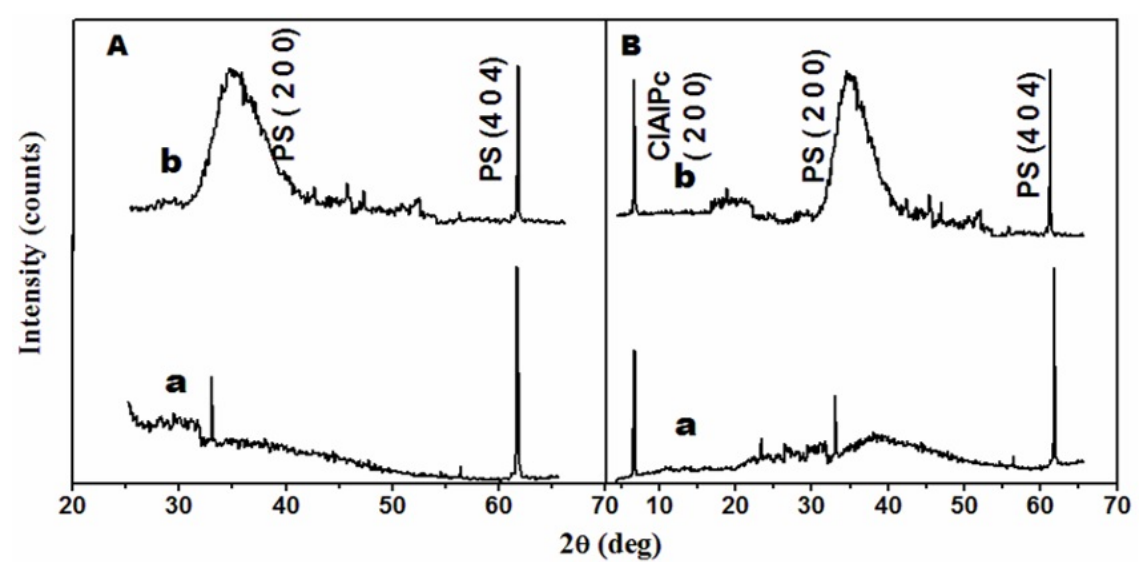

FIG. 1. XRD Pattern of the samples prepared at $30 \mathrm{~mA} / \mathrm{cm}^{2}$ for (a) $10 \mathrm{~min}$ (b) $60 \mathrm{~min}$ : (A) PS (B) ClAlPc/PS

peak shown by the sample prepared at $30 \mathrm{~mA} / \mathrm{cm}^{2}, 60 \mathrm{~min}$ indicates that it is more nanostructured in nature. The crystallite sizes calculated from Scherrer's approximation are in the range from 12 to $61 \mathrm{~nm}$.

\subsection{Scanning electron microscope}

The SEM image of the PS sample is shown in Fig. 2. The porosity of the sample increases with increasing etching time [6]. The porosities calculated from gravimetric method were shown to range from $55 \%$ to $78 \%$.
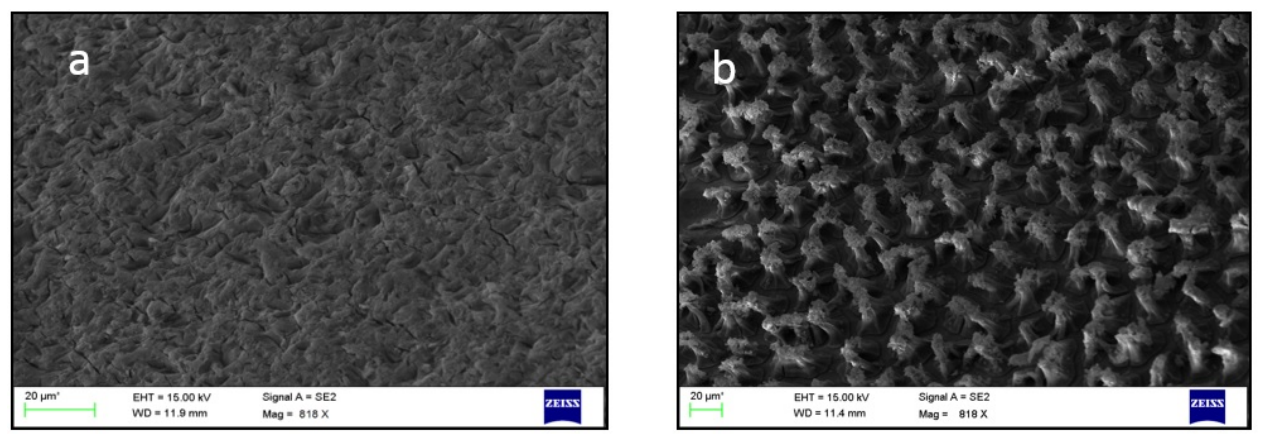

FIG. 2. SEM image of PS samples prepared at $30 \mathrm{~mA} / \mathrm{cm}^{2}$ for etching time (a) $10 \mathrm{~min}$ (b) $60 \mathrm{~min}$

\subsection{Optical measurements}

The optical band gap measurements were carried out using UV absorption and PL emission for PS and ClAlPc/PS samples at room temperature. The PL emission spectra of PS and ClAlPc/PS samples are shown in Figs. 3A and 3B respectively. The calculated band gaps from PL and UV measurement are shown in Table 1. The values are in good agreement with each other.

The band gaps of the PS samples are blue shifted from the bulk silicon $(1.1 \mathrm{eV})$. Also, the band gaps of the PS samples are slightly blue shifted with increased etching time. This shift in band gap (band gap widening) is because of quantum confinement due to reduction in the size of the Si nanocrystallites for increased etching time [7]. The decrease in crystallite size is attributed to the increase in porosity with increased etching time [8]. The PL intensity of the PS samples increases with increasing etching time due to the increase in the total volume of the nanocrystallites on the surface of the PS $[9,10]$.

For the dye sensitized PS (ClAlPc/PS), the PL emission is shifted to $735 \mathrm{~nm}$ (Fig. 3B(a)) compared to the PS sample which is attributed due to the presence of chlorine in the dye. The decrease in PL intensity shown by ClAlPc/ PS with increasing etching time is explained due to the enhanced absorption with an increase in porosity and confinement of particles into a lower dimension [11]. The minimum emission intensity shown by ClAlPc/PS at a current density of $30 \mathrm{~mA} / \mathrm{cm}^{2}$ with etching time of $60 \mathrm{~min}$ (Fig. 3B) indicates that it is a good absorber of radiation and can be used for solar cell application. 


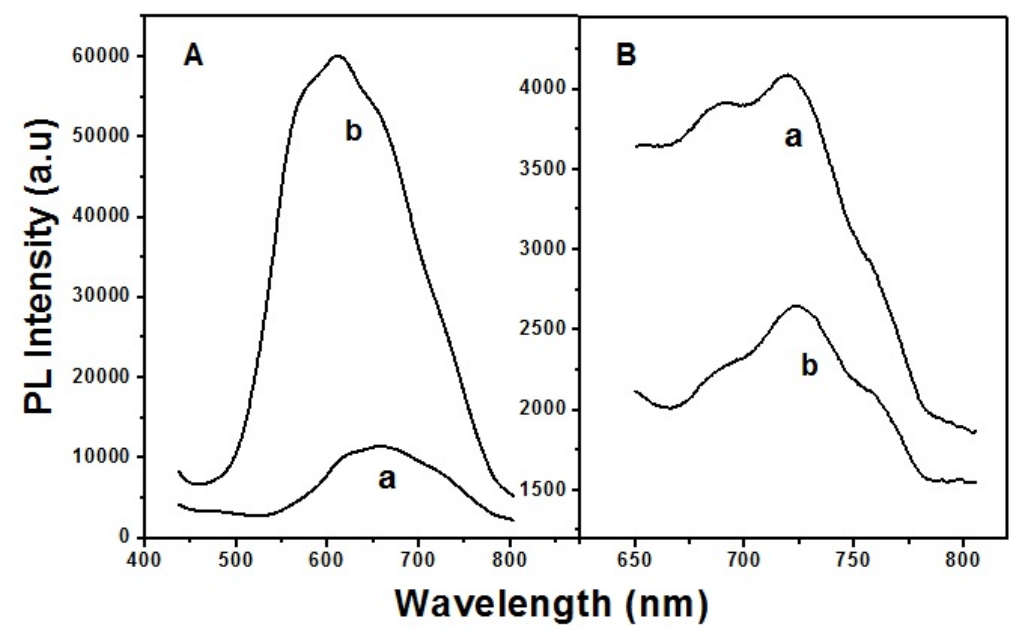

FIG. 3. Photoluminescence spectra of PS samples prepared at $30 \mathrm{~mA} / \mathrm{cm}^{2}$ for (a) $10 \mathrm{~min}$ (b) 60 min: (A) PS

TABLE 1. Bandgap of the samples

\begin{tabular}{|c|c|c|c|c|}
\hline \multirow{2}{*}{ Etching time } & \multicolumn{4}{|c|}{ Band gap (eV) } \\
\cline { 2 - 5 } & \multicolumn{2}{|c|}{ PS } & \multicolumn{2}{c|}{ ClAlPc/PS } \\
\cline { 2 - 5 } & PL & UV & PL & UV \\
\hline a (10 min) & 1.81 & 1.81 & 1.60 & 1.59 \\
\hline b $(60 \mathrm{~min})$ & 2.02 & 2.05 & 1.76 & 1.77 \\
\hline
\end{tabular}

\subsection{I-V Measurements}

Performance of DSSCs $\left(1 \mathrm{~cm}^{2}\right.$ size) was analyzed by current-voltage (I-V) characteristics. Photocurrents and voltages were measured using a Keithely source meter 2400, with an $80 \mathrm{~W}$ halogen lamp and AM $1.5 \mathrm{G}$. The conversion efficiency of the samples is given in Table 2. The literature value of conversion efficiency of $\mathrm{ClAlPc} / \mathrm{TiO}_{2}$ is $2.1 \%$ [12].

TABLE 2. Conversion efficiency of the ClAlPc/PS samples (Current density $30 \mathrm{~mA} / \mathrm{cm}^{2}$ )

\begin{tabular}{|c|c|c|}
\hline & Porosity of PS (\%) & Efficiency (\%) \\
\hline a (10 min) & 55 & 0.84 \\
\hline b $(60 \mathrm{~min})$ & 78 & 2.84 \\
\hline
\end{tabular}

\section{Conclusion}

Nanostructured porous silicon (PS) samples were prepared at constant current density of $30 \mathrm{~mA} / \mathrm{cm}^{2}$ at etching times of 10 and $60 \mathrm{~min}$. The samples were characterized by XRD, UV-Vis and PL emission techniques. The band gap increases with increased etching time. To study the effect of dye sensitizer, the surface of these PS samples was sensitized with derivative of Chloroaluminum Pc (ClAlPc). The dependence of absorption and emission intensities on these samples indicate that ClAlPc /PS prepared at current density of $30 \mathrm{~mA} / \mathrm{cm}^{2}$ with 60 min etching time is good absorber of radiations. The DSSC prepared by ClAlPc /PS shown a maximum conversion efficiency of $2.8 \%$ and can be used for solar cell applications.

\section{Acknowledgement}

The authors acknowledge the University Grant Commission (UGC), India, for financial support in the form of Major research project (F.No.41-941/2012 (SR)). 


\section{References}

[1] Regan B.O., Gratzel M. Low-Cost, High Efficiency Solar Cell Based on Dye Sensitized Colloidal TiO 2 Film. Nature, 1991, 353, P. 737-739.

[2] Smith R.L., Collins S.D. Porous silicon formation mechanisms. Journal of Applied Physics, 1992, 71(8), P. R1-R22.

[3] Azim-Araghi M.E., Krier A. The influence of ammonia, chlorine and nitrogen dioxide on chloro-aluminium phthalocyanine thin films. Appl. Surf. Sci., 1997, 119, P. 260.

[4] Hadi H.A., Ismail R.A., Habubi N.F. Fabrication and characterization of porous silicon layer prepared by photo-electrochemical etching in $\mathrm{CH}_{3} \mathrm{OH}: \mathrm{HF}$ solution. International Letters of Chemistry. Physics and Astronomy, 2013, 3, P. $29-36$.

[5] Jafari M.J., Azim-Araghi M.E. Gholami M. Chemiresistive Electrical Properties Of Chloroaluminum Phthalocyanine Nanostructured Thin Films. Optoelectronics And Advanced Materials, 2012, 6(9-10), P. 868-874.

[6] Khaldun A., Salman Z. Hassan., Khalid Omar. The effect of etching time of porous silicon on solar cell performance. Journal of Superlattices and Microstructures - Elesvier, 2011, 50, P. 647-658.

[7] Azim-Araghi M.E., Karimi-Kerdabadi E., Jafari M.J. Eur. Phys. J. Appl. Phys., 2011, 55, P. $302-303$.

[8] Srinivasan R., Jayachandran M., Ramachandran K. Photoacoustic studies on optical and thermal properties of p-type and n-type nanostructured porous silicon for (100) and (111) orientations. Cryst. Res. Technol., 2007, 42(3), P. 266-274.

[9] Kadhim Raheem G., Ismail Raid A., Abdulridha Wasna'a M. Structural, Morphological, Chemical and Optical Properties of Porous Silicon Prepared By Electrochemical Etching. International Journal of Thin Films Science and Technology, 2015, 4(3), P. 199-203.

[10] Kim D.A., Shim J.H., Cho N.H.. PL and EL features of p-type porous silicon prepared by electrochemical anodic etching. Appl. Surf. Sci., 2004, 234, P. 256-261.

[11] Jayachandran M., Paramasivam M., Murali K.R., Trivedi D.C., Raghavan M. Synthesis Of Porous Silicon Nanostructures For Photoluminescent Devices. Materphys. Mech., 2001, 4, P. 143.

[12] Walter M.G., Rudine A.B., Wamser C.C. Porphyrins and phthalocyanines in solar photovoltaic cells. J. Porphyrins Pthalocyanine, 2010, 14, P. 759-762. 